\title{
Signs of heat stress and some steps to reduce the negative effects on animals
}

\author{
Alsaied Alnaimy Mostafa Habeeb *, Samir Fathey Osman and Ahmed Elsayed Gad \\ Biological Applications Department, Radioisotopes Applications Division, Nuclear Research Center, Atomic Energy \\ Authority, Inshas, Cairo, Egypt, P.O.13759.
}

Publication history: Received on 04 July 2020; revised on 12 July 2020; accepted on 17 July 2020

Article DOI: https://doi.org/10.30574/gscarr.2020.4.1.0058

\begin{abstract}
The thermal comfort region for greatest animals is between $4{ }^{\circ} \mathrm{C}$ and $25^{\circ} \mathrm{C}$. When temperature surpasses $25{ }^{\circ} \mathrm{C}$, animals suffer heat stress. In severe heat stress, the profound body temperature increases, animal cells are affected and production performance is reduced. Most physiological and biochemical variations could occur to protect essential cell functions in contradiction of heat stress and to permit a fast recovery from moderate hypothermic destruction. In tropical and subtropical countries, the climatic characteristic is the major constraint on animal productivity. Production and reproduction are reduced as a result of the extreme changes in biological functions affected by heat stress. Reduction of the negative effects of heat stress can be reduced or even eliminate those losses to improve its productivity has been attempted using different techniques including physical, nutritional, and physiological means.
\end{abstract}

Keywords: Heat stress; Animal; Critical temperature; Temperature-humidity index; Production; Reproduction

\section{Introduction}

Best climatic conditions for animals would be something like an air temperature of 13 to $20{ }^{\circ} \mathrm{C}$, wind velocity of 5 to 18 $\mathrm{km} /$ hour, the relative humidity of 55 to $65 \%$, and a moderate level of sunshine, and these factors are interrelated. Ambient temperature is related to other climatic factors but the relationship with the relative humidity seems to be the most important, since the feeling of warmth under high ambient temperature increases with high relative humidity percentage. Such a relationship induced to propose a measurement of the level of severity of heat stress using the two factors and was termed the temperature-humidity index. The effect of heat stress is enlarged when the relative humidity is larger than 50\% [1]. In tropical and subtropical countries, the climatic characteristic is the major constraint on animal productivity. Production and reproduction are impaired as a result of the drastic changes in biological functions caused by heat stress [2]. According to the World Health Organization, World Meteorological Organization, and the United Nations Environmental Program, global warming would be a greater frequency and greater duration of exposure to hotter temperatures, especially, during the summer months. Typical hyperthermia sometimes occurs during severe heat in summer and as a result of hard expose to the sun throughout the world [3].

\section{Heat stress}

Heat stress is the state at which body mechanisms activate to sustain an animal's thermal balance when exposed to uncomfortable elevated ambient temperature. Heat stress occurs when any combination of the environmental conditions causes the effective temperature of the environment to be higher than the animal's thermo-neutral (comfort zone) [4]. Heat stress when an animal misses the ability to dissipate sufficient heat to maintain thermal balance and her body temperature increases. This harms dry matter intake, production, and reproduction [5]. Animal experiences heat stress when an animal loses the ability to dissipate sufficient heat to maintain thermal balance and body temperature

\footnotetext{
* Corresponding author: Alsaied Alnaimy Mostafa Habeeb, Mobile: 002-01014456768,E.mails: dr_alnaimy@yahoo.com
} 
escalations. Heat stress defined as the state at which the animal body's physiological mechanisms activate to maintain the body's thermal balance when animals exposure to elevated temperature [6, 7].

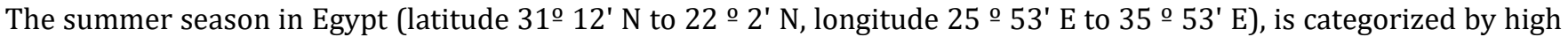
ambient temperature $\left(35-40{ }^{\circ} \mathrm{C}\right)$, high relative humidity (50-75\%) and high solar radiation $(4500 \mathrm{KJ} / \mathrm{M} 2)$ with extreme observed during the periods of greatest heat stress which normally extends about 6 months from May to October. Animals under such conditions of the year become uncomfortable suffering extremely in their production and reproduction [8,9]. Exposure of animals to uncomfortable conditions brings some sequences of risky changes in the biological functions, which include a decrease in feed intake and utilization as well as conflicts in water, protein, energy and mineral balances and blood biochemical components finale to deficiency the productive and reproductive performance and lowers natural immunity making animals more vulnerable to disease $[10,11]$.

\section{Lower (LCT) and upper critical temperature (UCT)}

After environmental temperatures change out of the comfortable temperature (Thermo-neutral, THN), dairy cattle begin to experience either heat stress or cold stress. Both stresses require the animal to increase the quantity of energy used to continue the body temperature stable and there is less energy available to produce their products. Thermoneutral region is the range of temperatures where animal normal body temperature is kept steady and heat production is at the basal level [12]. The ranges of the thermo-neutral zone are from lower critical temperature (LCT) to upper critical temperature (UCT). The lower critical temperature is the environmental temperature at which animal requirements to increase metabolic heat production to continue body temperature. The upper critical temperature is the environmental temperature at which the animal increases heat manufacture as a concern of an increase in body temperature subsequent for insufficient evaporative heat loss.

Thermo-neutral state depends on the age, breed, feed intake, diet composition, the previous state of temperature acclimatization, production, housing system, stand conditions, skin fat insulation, outside coat protection, and the activities of the animal. The upper critical temperature is given as $25-26^{\circ} \mathrm{C}$, lower critical temperature as a range from -16 to $-37 \stackrel{\circ}{\circ} \mathrm{C}$ for the animal [13]. The lower critical temperature for newborn calves is $10{ }^{\circ} \mathrm{C}$ in the dry and draught-free environment and decreases to $0{ }^{\circ} \mathrm{C}$ by the time the calf is 1 month old [14].

\section{Temperature-humidity index (THI)}

The environmental temperature, relative humidity, photoperiod, solar radiation, and wind velocity seemed to be interrelated in the subtropical climate. However, the relationship of environmental temperature with the relative humidity looks to be the most important, since the sensitivity of heat increases with increases relative humidity percentage [15]. Such association planned measurement of the level of the sternness of heat stress using both environmental temperature and relative humidity and was called temperature-humidity index (THI). The expressions for describing how animals reply to thermal challenges have been defined by the International Commission for Thermal Physiology [16]. THI could be used as a sign of warm air climatic conditions. THI is a measurement by calculation from the relative humidity and the air temperature and is calculated for a specific day. The THI value is that as the relative humidity at any temperature increases and it becomes increasingly more difficult for the animal to cool itself. However, THI of 70 or lower are revealed comfortable, 75-78 are stressful and higher than 78 are excessive stresses [17]. Animal involvement heat stress when the THI increases above 72. Table 1 shows ambient temperature and relative humidity arrangements that produce mild heat stress (THI 72 to 79), moderate heat stress (THI 79 to 89), and severe heat stress (THI > 89).

An animal has numerous mechanisms to aid dissipate body heat. These mechanisms include conduction where the animal conducts heat to any cooler surface; convection where heat flows leave the animal's body; radiation where the animal releases heat to any cooler environment and evaporation where wetness is evaporated from the external of animal's body (sweating) and animal lungs (panting). The animal will also decrease feed intake to produce a lesser amount of metabolic heat which is a protecting mechanism [18]. Heat stressed animals are less possible to display standing estrus and commonly exhibit signs of estrus at night when the temperature is cooler. Besides, the length of estrus is shorter for animals exposed to heat stress $[19,20]$. Exceeding the upper critical environmental temperature related to the decline of the productive and reproductive performance of animals [21]. 
Table 1 Temperature Humidity Index (THI)1 for dairy cows [1].

\begin{tabular}{|c|c|c|c|c|c|c|c|c|c|c|c|c|c|c|c|c|c|c|c|c|c|}
\hline \multirow{2}{*}{$\begin{array}{l}\text { Deg. } \\
\text { F }\end{array}$} & \multicolumn{21}{|c|}{ Relative Humidity } \\
\hline & 0 & 5 & 10 & 15 & 20 & 25 & 30 & 35 & 40 & 45 & 50 & 55 & 60 & 65 & 70 & 75 & 80 & 85 & 90 & 95 & 100 \\
\hline 75 & & & & & & & & & & & & & & 72 & 72 & 73 & 73 & 74 & 74 & 75 & 75 \\
\hline 80 & & & & & & & 72 & 72 & 73 & 73 & 74 & 74 & 75 & 76 & 76 & 77 & 78 & 78 & 79 & 79 & 80 \\
\hline 85 & & & 72 & 72 & 73 & 74 & 75 & 75 & 76 & 77 & 78 & 78 & 79 & 80 & 81 & 81 & 82 & 83 & 84 & 84 & 85 \\
\hline 90 & 72 & 73 & 74 & 75 & 76 & 77 & 78 & 79 & 79 & 80 & 81 & 82 & 83 & 84 & 85 & 86 & 86 & 87 & 88 & 89 & 90 \\
\hline 95 & 75 & 76 & 77 & 78 & 79 & 80 & 81 & 82 & 83 & 84 & 85 & 86 & 87 & 88 & 89 & 90 & 91 & 92 & 93 & 94 & 95 \\
\hline 100 & 77 & 78 & 79 & 80 & 82 & 83 & 84 & 85 & 86 & 87 & 88 & 90 & 91 & 92 & 93 & 94 & 95 & 97 & 98 & 99 & \\
\hline 105 & 79 & 80 & 82 & 83 & 84 & 86 & 87 & 88 & 89 & 91 & 92 & 93 & 95 & 96 & 97 & & & & & & \\
\hline 110 & 81 & 83 & 84 & 86 & 87 & 89 & 90 & 91 & 93 & 94 & 96 & 97 & & & & & Mil & Ju & & & \\
\hline 115 & 84 & 85 & 87 & 88 & 90 & 91 & 93 & 95 & 96 & 97 & & & & & & & $\mathrm{Me}$ & ium & tress & & \\
\hline 120 & 88 & 88 & 89 & 91 & 93 & 94 & 96 & 98 & & & & & & & & & & res & ess & & \\
\hline
\end{tabular}

Explaining the mechanisms involved in increased heat loss when the body becomes overheated. Guyton [22] listed that overheating encourages the preoptic thermostatic region to increase the rate of heat loss from the body in three different means:

- By stimulating the sweat glands to cause evaporative heat loss from the skin

- By stimulating vasodilator nerves to the skin by this means increasing the transport of the heat by the blood to the body external.

- By stopping sympathetic centers in the posterior hypothalamus to eliminate the normal vasoconstrictor manner to the skin vessels and by this means let more vasodilatation.

Production and reproductive performance in animals are reduced as a result of the severe changes in biological functions which decrease about $50 \%$ from the productivity of temperate breeds when introduced to the tropical or subtropical countries due to heat stress [23, 24]. Exposure animals to high air temperature encourage the peripheral warm air receptors to transfer suppressive nerve impulses to the appetite center to decrease the feed consumption for minimizing heat load on animals. Therefore, fewer substrates converted for hormone synthesis and heat production. Feed intake initiates to decline at air temperatures of $25-26^{\circ} \mathrm{C}$ in animals and reduces more speedily above $30^{\circ} \mathrm{C}$ and decline by as much as $40 \%$ at $40^{\circ} \mathrm{C}$ [27], $22-35 \%$ in goats [28] or $8-10 \%$ in buffalo heifers [29]. Reducing feed intake is the way to decrease heat production in warm situations like the heat increment of feeding is an important cause of heat production in animals [17]. As a result of the stage of negative energy balance, as a result, body weight and body condition score go depressed [30]. Exposure animals to severe heat stress defeat the production of hormone-releasing factors from the hypothalamic centers to decrease the pituitary hormonal secretion and consequently lowers the secretion of the thyroid hormones finale to deficiency of production and reproduction of animals [2]. Besides, a high level of cortisol detected in the animals exposed to heat stress may be associated with depression in animal production [25]. Animals commonly respond to heat stress conditions by eating less food, thus certainly controlling the increase in deep body temperature due to digestion. Respiratory rate increases and there is a manifest increase in insensible heat loss by evaporation of water from the lungs. Animals also drink at least 5 times the amount of water under temperate conditions as well as urine output increases and most mineral ions are missing [26]. Exposure of animals to excessive environmental temperature encourages the nerve impulses to the specific centers in the hypothalamus to increase the evaporative and non-evaporative cooling systems and the adaptive mechanisms to help in preventing the increase in animal body temperature. Prolonged heat exposure suppresses the production of hormone-releasing factors from the 
hypothalamic centers causing reductions in pituitary hormones. These decreases in both substrate and hormones with a rise in body temperature inhibit the enzymatic activities, which decrease the metabolism and accordingly impair production and reproduction $[6,7]$.

\section{Signs of heat stress on animal $[1,5]$}

- $\quad$ Reduced activity.

- Restlessness and crowding under shade.

- Increased salivation.

- Increased respiration rate: 80 to $120 \mathrm{bpm}$ under moderate heat stress, 120 to $160 \mathrm{bpm}$ under strong heat stress, and over $160 \mathrm{bpm}$ under severe heat stress.

- $\quad$ Rates of the gut and ruminal motility are reduced

- Lethargy and decreased activity.

- Decreased feed intake: feed intake decreased by $>10-15 \%$ at $25-27 \stackrel{\circ}{\circ} \mathrm{C}$ with a marked decline of $40 \%$ above 30 ${ }^{\circ} \mathrm{C}$. The feed intake of animals at $40^{\circ} \mathrm{C}$ is reduced by $20-40 \%$. During heat stress, DMI, gut motility, rumination, ruminal contractions are reduced due to depressing animal appetite by having a direct negative effect on the appetite center of the hypothalamus [31].

- Increased sweating: In animals, two types of sweating can be distinguished: both are involved in heat dissipation. The first type is insensible sweating or perspiration that leaves the body at all times unless the relative humidity is $100 \%$. The second kind is thermal sweating occurs as the principle evaporative cooling mechanism of the animal when the environmental temperature increases [32].

- Increased rectal temperature ( $>102.6 \mathrm{~F}$ ). The normal temperature of animals is $101.5 \mathrm{~F}$. Rectal temperature is an indicator of thermal balance and may be used to evaluate the adversity of the high environmental temperature. In severe conditions of heat stress the rectal temperature increase. The effect is increased when the relative humidity is greater than $50 \%$. A rise of $1 \stackrel{\circ}{\circ}$ or less is enough to reduce performance in most animals [33].

- $\quad$ Reduced heart rate: The normal panting is 35-45 breathing while under heat stress, panting increased to $>80$ breaths per minute. The initial increase in heart rates slows down when the heat stress persists. Reduced heart rate is more usual in the heat-stressed animal as it is concomitant with the reduced rate of heat production as a reaction to high environmental temperatures.

- Increased water intake: Heat stress increases water intake by 5 times the normal level in temperate regions. Water and macro-mineral needs subjective heavily by demands to sustain homeostasis and homeothermy are changed for animals during heat stress. Lactating animals have a large turnover of water and electrolytes [34]. Warm air stress increases water and electrolyte metabolism. Extreme water intake during the hot period was at the lowest doubled from the water intake under a comfortable climate. This is mainly due to lower plasma concentrations of metabolic hormones [31].

- Increased animal water content: The total body water is estimated to range between 75 and $81 \%$ of the bodyweight for animals. Heat stress concurrently influences water metabolism [35]. Under current stress, animals tend to have increased water content in the rumen as a result of a faster water turnover rate. Water loss from an animal is a continuous process; taking place all the time and increasing during the heat stress due to further evaporative water loss. Water intake of an animal under heat stress increases progressively [36].

- Reduced milk production by $10-20 \%$ or more. It is accepted that heat stress is the major cause of lost production in animals in hostile regions. Production of animals is reduced by $15 \%$, accompanied by a $35 \%$ decrease in the efficiency of energy utilization for productive purposes when the animal is transferred from an air temperature of 18 to $30 \stackrel{\circ}{\circ}$. Animal production declines as a direct result of high ambient temperatures due to the negative effects the heat stress on the secretory function of the udder [35].

- Metabolic responses are reduced: under heat stress metabolism is reduced due to reduced thyroid hormone secretion and gut motility, resulting in increased gut fill. Plasma growth hormone concentration and secretion rate decline with hot temperatures. Ruminal pH is normally lower in the heat-stressed animal.

- Great changes in dietary electrolyte balance and acid/base balance associated with heat stress. The major electrolytes involved in dietary electrolyte balance are $\mathrm{Na}+, \mathrm{K}+, \mathrm{CL}^{-}$are the main ions involved in sweat [37].

- Heavy loss of electrolytes: evaporative heat loss through sweating and panting is the primary mechanism for heat loss at great environmental temperatures. As a result of water loss from sweating, thirst is increased and more urine is excreted and the huge water flux resulting from increased water consumption also causes heavy loss of electrolytes. Potassium loss from the skin increases by $500 \%$ in heat-stressed animals and in attempts to conserve potassium, animals increase urinary excretion rates of sodium. 
- In high temperatures, there is panting respiration to cool the body by evaporative cooling. The rapid loss of C02 results in respiratory alkalosis. Animals compensate by increasing the urinary output of HC03-. Persistent replacement of this ion is serious to the controlling of blood chemistry. Heat stress increases dietary requirements for the key electrolytes, $\mathrm{Na}+\mathrm{K}+$, and HC03-. Therefore dietary electrolyte balance is important in locations where environmental temperatures exceed $24{ }^{\circ} \mathrm{C}$ and are exacerbated if relative humidity exceeds $50 \%$. Running of the dietary electrolyte balance is based on addition essential body salts and electrolytes to the drinking water and feed. It stabilizes the dietary electrolyte balance, promotes homeostasis, assists the osmoregulation of body fluids, stimulates appetite, and ensures normal skeletal development. Animal sweat contains a large amount of potassium. Mineral recommendations during heat stress include: Potassium: $>1.4 \%$ of DM, Sodium: 0.35 to $.45 \%$ of DM Magnesium: 0.35 to $0.40 \%$ of DM and Chlorine: $<0.40 \%$ of DM. Mineral alterations should be prepared several weeks before the onset of high temperatures so minerals are present in the body when needed. Several feed additives, such as Buffer and yeast culture, have shown benefits when addressing heat stress [38].

\section{Oxidative stress in animals exposed to heat stress}

The terms oxidative stress, oxidative damage, free radical and antioxidant have become an integrated part of the variety of scientific discussions in issues related to chemistry, biology, and research in biosciences. Oxidative stress commonly occurs following heat stress in tropical regions and affects negatively on animal's performance. The adverse effect of heat stress harmed enzymatic activity [39]. Glutathione (GSH) is an antioxidant in animals protects cells from oxidative damages and is capable of preventing damage to important cellular components caused by reactive oxygen species such as free radicals, peroxides, lipid peroxides, and heavy metals. GSH has been mediating the initial response for acquiring tolerance to heat stress. GSH serves vital functions in animals, antioxidant defense, scavenging free radicals, and other reactive species, removing hydrogen and lipid peroxides, preventing oxidation of bio-molecules, signal transduction, and gene expression and DNA and protein synthesis, and proteolysis. Different kinds of stress result in a reduction in the concentration of reduced GSH in animal organs. GSH synthesis is impaired under stress conditions, leading to GSH deficiency. A decrease in GSH and an increase in GSSG were found in the blood of heat-stressed cattle. Significant inhibition of total ATPase activity and cholinesterase enzymes were found in animals under heat stress conditions [40]. Fast production of free radicals and reactive oxygen species and/or a decrease in antioxidant defense mechanisms result in oxidative stress [41]. The effect of heat stress is known to induce oxidative stress which induces the production of reactive oxygen species (ROS). The high production of ROS and a decrease in antioxidant defense lead to the cause of many diseases and leading to the onset of health disorders in cattle [42]. Roles for GSH in signal transduction, gene expression, apoptosis, protein glutathione-relation, and nitric oxide metabolism are well discovered [43]. Specifically, several studies have led to the free radical theory of human diseases and to the advancement of nutritional therapies to improve GSH status under various pathological conditions [44]. Most recently, studies of GSH turnover were initiated to provide much-needed information about quantitative aspects of GSH synthesis and catabolism in the animal body and specific cell types. Adequate protein nutrition is crucial for the maintenance of GSH homeostasis in animal enteral or parenteral cystine, methionine, $\mathrm{N}$-acetyl-cysteine, and l-2-oxothiazolidine-4-carboxylate are effective precursors of cysteine for tissue GSH synthesis [45].

The dietary of antioxidant nutrients is important in protecting tissues against free radical damage since free radical reactions are an integral part of normal metabolism. The antioxidant function enhances immunity by maintaining the structural and functional integrity of the immunity system. The reduction in immunity will affect animal production efficiency through increased susceptibility to diseases, thereby leading to increased animal morbidity and mortality [46]. The protection against free radical damage by the dietary of antioxidant nutrients has become very important in the studies related to ruminant production and reproduction. Antioxidant status gives complementary information about the metabolic status of the animal rather than metabolic parameters alone [47]. Oxidative stress markers can be divided into non-enzymatic antioxidants and antioxidant enzymes such as superoxide dismutase, catalase, and glutathione peroxidase [48]. Oxidative stress commonly occurs following heat stress in tropical regions and affects animals and Glutathione protects cells from oxidative damages. The oxidative balance is affected during heat stress periods. Fast production of free radicals and reactive oxygen species and/or a decrease in antioxidant defense mechanisms result in oxidative stress [41].

\section{Steps to reduce heat stress}

Good management should aim to well-being, comfort, and maintaining the highly productive and reproductive efficiency of the animals. Under hot climate conditions, the major objective is to facilitate overcoming heat stress, although such 
criteria are sometimes difficult because of its occasional high costs, altogether with that most countries in which it occurs have severe financial constraints. Providing suitable housing, feeding, disease, and parasite control and heat stress alleviation practices, together with amelioration of the environment, can help heat-stressed animals to express their genetic potentials in tropical and sub-tropical areas $[49,50]$. Although we cannot change the weather, we can modify the animal's environment to minimize heat stress and we can change feeding practices. Two main management practices have been proposed to ameliorate the effects of heat stress: physical protection and nutritional dietary manipulation.

\subsection{First one: Physical protection}

The physical technique includes shading and cooling methods. Any cooling system that is to be effective must be into consideration the intense solar radiation, high ambient temperature, and the typically high daytime relative humidity. These challenging conditions tax the ability of any cooling system to maintain normal body temperature for the animals.

\subsubsection{Natural shade}

Trees are an excellent normal source of shade on the grass. Trees are not operative blockers of solar heat but the evaporation of moisture from leaf surface cools the immediate air.

\subsubsection{Artificial shade}

Solar radiation is a major factor in heat stress. Obstructive its effects through the use of accurately built shade structures alone increase production strangely. Two options are available: permanent shade structures and portable shade structures [51].

\subsubsection{Permanent shade structures}

Major design parameters for permanent shade structures (orientation, floor space, height, ventilation, roof construction, feeding and water facilities, waste management system) depend on climate conditions. In hot and humid climates the alignment of the long-axis in an east-west direction achieves the maximum amount of shade and is the preferred orientation for tied animals, its north to south direction is better where animals are free to move. Space requirements are essentially doubled in a hot climate. Normal air program under the stable shade structure is affected by height and width, the slope of the roof, the size of the edge opening, etc. Painting metal roofs white and adding insulation directly under the roof will reflect and insulate solar radiation and reduce thermal radiation on animals.

\subsubsection{Portable or temporary shades}

Portable shades offer some advantages in their ability to be moved to a new area in different pastures. Portable shade cloth, as well as a light roofing material, may be used on the temporary shades.Shading is one of the most important and cheapest ways to modify the cow's environment during hot weather. It is reported that cows shaded during the dry period gave birth to larger calves and had greater 100-day and 305-day milk yields than un-shaded dry cows. The shed should be placed on a top of a hill if possible, opened on all sides, and with wire or cable fences, the roof should be 3.5 to 4.0 meters high with its long dimension east-west to prevent exposure to high solar radiation. The roof slopes should be south-north to avoid vertical sun heat. The roof can be made of a 10 to $15 \mathrm{~cm}$ layer of hay held in place by wire above and below that realizes insulating and cool effects. Such a roof does not permit penetration of heat from the sun through to radiate into the animals, as well as, little radiant animals are reflected from its underside [52]. Also, hot air under the shade can rise through the loose hay. If solid insulating material or wood shads roofs are used, the top should be painted white or shiny to reflect as much heat as possible, and the underside should be dull and dark to avoid reflecting animal heat it receives. The pens should be constructed of wire or cables to offer less resistance to air movement. The adequate surface area from shade per animal is 3.7 - 5.6 square meters for cattle and 1.86-2.79 square meters for sheep to be kept loose in the shed. Vegetation should surround the pens. Shade trees (with falling leaves during winter) should be scattered around and within the yards of the sheds, and such sheds should be scattered in the pasture or range. If livestock owners are compelled to build for housing their animals, they have to use insulating materials for the outer walls with adequate ventilation openings and the roofs should erect $60 \mathrm{~cm}$ more than the outer walls to protect the walls from direct sun heat. One of the first steps that should be taken to moderate the stressful effect of a hot climate is to protect the animals from direct and indirect solar radiation. It was estimated that the total heat load could be reduced from 30 to $50 \%$ with a well-designed shade [52]. 


\subsubsection{Fans and Sprinklers}

Several options are available. However, if you are going to put water on cows, air movement with fans is a necessity. Sprinklers should wet the cow but not the udder. Fans should move enough air to evaporate the water. Sprinklers can be controlled with timers to cycle the water on and off (i.e. 5 minutes on and 10 minutes off in a 15-minute cycle). Fans and sprinklers are usually placed near the feed bunk. The coolest place in the barn should be near the feed bunk to encourage eating. Fans, but not sprinklers, may be placed over free stalls. Fans and sprinklers should also be used in the holding area where temperatures increase rapidly when cattle are concentrated before milking. Habeeb et al. [53] studied the role of niacin and sprinkling in improving milk yield composition and biochemical functions of the heatstressed Friesian cows. The authors reported sprinkling the heat-stressed lactating cows with tap water caused a significant increase in milk yield (16.7\%), milk protein $(6.7 \%)$, and milk fat $(6.0 \%)$ contents and a significant decrease in ash content (15.3\%). The increase in daily milk yield, milk composition, and most blood components in the heatstressed cows due to sprinkling may be attributed to that sprinkling cooled the animal's surface directly by conduction and evaporation (2427 joules dissipated per g water evaporated). The result was reducing the heating load of the summer season by increasing the heat loss through skin vaporization. This reduction in heat load improved the appetite of the animal to increase feed intake and consequently proteins utilization either from feed or from digested rumen microorganisms, are increased. The increase in milk yield and composition may be also due to the role of sprinkling in alleviating the thermal hormonal alterations which depress the milk yield under heat stress, i.e., increase T3 level and decrease cortisol level in sprinkled animals compared with not sprinkled. Consequently, the energy used for cooling processes may be spared for production functions. Moreover, sprinkling aids animals to reach a steady physiological state as indicated by restoration in blood components as well as a reduction in serum transaminases enzyme activities [38].

\subsubsection{Sprinkler and fan cooling systems (Direct evaporative cooling)}

Sprinkling uses a large water droplet size to wet the hair coat to the skin. Cooling is accomplished as water evaporates from the hair and skin. Upper body sprinkling followed by forced-air ventilation reduces body temperature; increase feed intake and milk yield. Sprinkling the heat-stressed animals with tap water alleviates the heat stress on respiratory and cardiovascular systems resulting in the significant decreases in respiration and pulse rates. Sprinkling also cooled the animal's surface directly by conduction and evaporation resulting reduction in the rectal temperature of the treated animals as compared to not sprinkled animals. The decrease in rectal temperature, respiration rate, and pulse rate and the increase in hemoglobin and packed cell volume values in the sprinkled animals may be due to increasing the heat loss through skin vaporization and at the same time, alleviating thermal hormonal alterations. The vaporization of $1 \mathrm{ml}$ of water requires 2.43 joules to convert into vapor and this is the amount of heat lost when 1 ml of the sweat evaporates from the skin [54]

\subsubsection{Sprayers in parlor exit lanes}

Exit lane sprayers are designed to automatically spray water onto the cows as they pass through.

\subsubsection{Reducing ambient air temperature for cooling the animal}

Air temperature of micro-environment can be lowered by air conditioning or refrigeration but the expense of such types of air cooling makes these impractical.

\subsubsection{The evaporative cooling}

The evaporative cooling pad (corrugated cardboard or similar material) and a fan system that uses the energy of air to evaporate water is a more economically feasible method to cool the micro-environment.

\subsubsection{Fine mist injection apparatus}

Recent design of micro-environment was using evaporative cooling systems by fine mist injection apparatus. This apparatus injects water under high pressure into a stream of air blown downward from above. Coolers are positioned in the roof of the shade structures or cowsheds and air are pulled through the cooler at very high rates. This system is effective in arid climates.

\subsubsection{High-pressure foggers disperse}

High-pressure foggers disperse is a very fine droplet of water which quickly evaporates, cooling the surrounding air and raising the relative humidity. The typical design incorporates a ring of fogger nozzles attached to the exhaust side 
Habeeb et al. / GSC Advanced Research and Reviews, 2020, 04(01), 046-058

of the fan. As fog droplets are emitted they are immediately dispersed into the fan's air stream where they soon evaporate. Animals are cooled as the cooled air is blown over their body and as they inspire the cooled air.

\subsubsection{Misters}

A mist droplet is larger than a fog droplet but cools the air by the same principle. These systems do not work well in windy conditions or in combination with fans in humid environments, where mist droplets are too large to fully evaporate before setting to the ground. The consequence is wet bedding and feed.

\subsubsection{Enhancing the animal's natural mechanism of heat loss}

Cooling in hot and humid climates emphasizes shade, wetting the skin, and moving air to enhance the animal's major mechanism for the dissipation of heat as evaporative cooling from the skin. The internal cooling technique (drinking cool or cold water) acts through the difference between the cool drinking water and warm urine execration temperature which helps in heat dissipation by conduction and also aids in evaporative cooling from the body surface $[55,56]$. Conclusively, drinking cool water is a method used to reduce the heat load on farm animals. The importance of the drinking cool water under hot climate may be attributed to the direct effect of the cooling process which aided animals to reach a steady physiological state with respect hemodilution normally occurring in heat-stressed animals. It is also possible that this cooling treatment improved the appetite of animals thus causing an increase in feed intake, especially, protein either from feed or from digested rumen microorganisms and consequently an increase in blood substrates, minerals, and vitamins. It is concluded that drinking cool water is an ideal mean and easier technique for improving the productive performance of animals under the summer season [57].

\subsubsection{Shearing process}

Effect of the wool shearing process during the hot summer season on some physiological, nutritional and growth performance was studied by Habeeb et al. [58] and found that shearing lambs during summer season increased significantly the mean values of DM, OM, CP, CF and NEF digestibility percentages, improved significantly the nutritive values of ration (TDN and DCP), decreased significantly water intake, increased DM intake and body weight gain and improved feed conversion rate. Providing shearing resulted in reducing the adverse effects of heat stress in summer and in turn improved the metabolic media of shorn lambs to increase their productivity. Besides, providing shearing resulted in alleviating the burden of summer heat stress and consequently improved the heat tolerance of lambs raised under semi-arid conditions of the desert and resulted in decreasing the hostile effects of heat stress in summer and turn better the metabolic media of shorn lambs to increase their levels in proteins and thyroid hormones $\left(\mathrm{T}_{4}\right.$ and $\left.\mathrm{T}_{3}\right)[58,59]$

\subsubsection{Water}

The most serious nutrient needed by the animal is water. Water intake will rise by $30 \%$ or more during heat stress. Clean water should be provided to cows where they congregate during the day and while in the holding pen and return alley from the milking parlor. Using wet feeds in the ration or adding water to the ration can also help. Water is one of the most important nutrients required for the maintenance of life and is involved in many physiological functions essential for the maximum performance of farm animals. Water requirements vary and are regulated by many factors such as intake of dry matter, environmental temperature, and loss of water from the body tissues (57). Livestock needs a plentiful supply of good and clean water for normal rumen fermentation and metabolism, proper flow of feed through the digestive tract, good nutrient absorption, normal blood volume, and tissue requirements. The exposure of animals to elevated ambient temperatures induces an increase in the dissipation of excess body heat, to negate the excessive heat load. The dissipation of excess body heat is excluded by the evaporation of water from the respiratory tract and skin surface via panting and sweating [59]. Drinking cool water under hot climate maybe lead to the direct effect of the cooling process which aided animals to reach a steady physiological state with respect hemodilution normally occurring in heat-stressed animals. It is also possible that this cooling treatment improved the appetite of animals and causing an increase in feed intake, especially, protein either from feed or from digested rumen microorganisms and consequently an increase in blood substrates, minerals, and vitamins [60,61]. Drinking cool water is a method used to reduce the heat load on farm animals. The importance of the drinking cool water under hot climate may be attributed to the direct effect of the cooling process which aided animals to reach a steady physiological state with respect hemodilution normally occurring in heat-stressed animals. It is also possible that this cooling treatment improved the appetite of animals thus causing an increase in feed intake, especially, protein either from feed or from digested rumen microorganisms and consequently an increase in blood substrates, minerals, and vitamins. It is concluded that drinking cool water is an ideal mean and easier technique for improving the productive performance of animals under the summer season [56]. 


\subsubsection{Ration changes and management}

Rations need to be formulated to compensate for reductions in dry-matter. Lower fiber diets produce less metabolic heat, though care must be taken to ensure adequate fiber is still provided. Additional fat is an option when needing to increase energy while maintaining the necessary fiber. Preserve feed fresh by feeding during early morning hours and in the evening when animals have well appetites. Consider feeding only a third of the ration during the day and two thirds in the evening when temperatures are cooler. Adding a total mixture of ration preservatives, will retard feed heating in the bunk. Keep bunks free of spoiled feed to maximize the animal's appetite.

\subsection{Second one: Nutritional dietary manipulation}

\subsubsection{Nutritional dietary manipulation}

Supplementation of heat-stressed animals with protein, fat, vitamins, and mineral resources is required to correct their negative balances since heat stress induces a significant decrease in the DMI and a significant increase in excretion of urine and sweat containing minerals [62].

Feeds should be administered during the coolest periods of the day, i.e. in the early morning late in the evening or by night, under hot climate conditions. In extremely hot days, it is preferred to keep the animals in the sheds. Mineral resources supplementation correct minerals negative balances and consequently improved milk production [63, 64]. A sharp increase in the secretion of potassium through sweat occurs during hot climate conditions so feeding diets that have a high dietary cation-anion difference improved DMI and milk yield and regulation of acid-base balance [65].

The antioxidant activity is high in medicinal plants and antioxidants play an important role in inhibiting and scavenging radicals that protecting animals against infectious and degenerative diseases [66]. Some medicinal plant extracts and pure forms of active compounds were evaluated for their potential application as modifiers of rumen microbial fermentation to produce VFA which represents the main supply of metabolizable energy for ruminant [67]. Medicinal plant extracts can be used as an antioxidant agent as it inhibited the non-enzymatic peroxidation which may increase immunity and may help the animals to tolerate the heat stress [68]. The antioxidant activity of medicinal plants was due to it acts as a scavenger of oxygen free radicals and protects hemoglobin from oxidation and lowers the production of reactive oxygen species like superoxide anions, $\mathrm{H} 2 \mathrm{O} 2$ and nitrite radical generation [69]. Friesian calves under heat stress condition fed diets supplemented daily with Nigella sativa seeds improved body weight gain [68].

\subsubsection{Change in time of feeding}

Habeeb et al $(60,61)$ showed that ewes in groups fed at 1200 and $1500 \mathrm{~h}$ were better than ewes fed at $0900 \mathrm{~h}$ in physiological and nutritional aspects. Respiration rate and temperatures of rectal, skin, and ear values decreased significantly while daily feed intake, dry matter intake, and water intake values increased significantly due to late feeding time under summertime. Digestibility of DM, OM, CP, CF, and NFE, as well as TDN and DCP of diet, improved significantly in ewes fed at 1200 and $1500 \mathrm{~h}$ as compared to ewes fed at $0900 \mathrm{~h}$. The same authors concluded that late of feeding time decreased the heat load of the summer season on pregnant ewes and providing feed at $1200 \mathrm{~h}$ or $1500 \mathrm{~h}$ to the animal without adversely affecting performance under hyperthermia. Schwartzkopf-Genswein et al. [70] reported that cattle fed late $(21.00 \mathrm{hr})$ in the day gained marginally more weight than cattle fed in the morning (0900). The lowest ADG was observed for morning fed steers, whereas the highest ADG was recorded for evening fed steers. Cattle fed in the evening also had higher significantly daily dry matter intake than morning fed cattle. These results indicate that it may be beneficial to feed in the evening from a cold climate thermodynamics perspective because the heat produced during fermentation and metabolism is shifted to the evening when cold stress is more likely to occur. Besides, in regions where heat stress is a concern, evening feeding would help decrease any additional heat load that could occur if the animals were fed during the warmest part of the day. Simone [71] suggests that by altering feeding time to the afternoon or evening can help to alleviate heat stress. Heat is generated in the animal by the process of consuming and fermenting feed. Adjusting the time of feeding to late afternoon or evening will mean that additional heat generated from the feed will occur in the cooler hours of the day. Also, multiple feeding can be beneficial during hot weather by offering 20 to $40 \%$ of total feed delivery in the morning, and the remainder (60 to $80 \%$ ) in the evening will help to alleviate heat stress.

\section{Conclusion}

Animals raised under the hot summer season are suffering from severe climatic stress for almost 6 months of the year and become uncomfortable suffering extremely in production and reproduction. Exposure of animals to heat stress 
evokes a series of drastic changes in the biological functions ending to impairment the productive and reproductive performance Reduces the heat-stressed on animals can be applied by different techniques. The management practices concerned in hot climate involve modification of the environment, reducing the animal's heat production, and increasing its heat loss. Some techniques that can be used to help the animal in dissipating the heat load and to correct the negative effects caused by heat stress arc classified to physical, physiological, and nutritional techniques.

\section{Compliance with ethical standards}

\section{Acknowledgments}

This work was supported by Biological Application Department, Radioisotopes Applications Division, Nuclear Research Centre, Atomic Energy Authority, Inshas, Cairo, Egypt and all authors decided that no acknowledge any financial interest or benefit we have arising from the direct applications of our research.

\section{Disclosure of conflict of interest}

No any conflict of interest statement in this article.

\section{Disclosure of informed consent}

We informed consent from all individual participants included in this article review.

\section{References}

[1] Wiersma F. (1990). Department of Agricultural Engineering. The University of Arizona, Tucson (Cited in Armstrong, 1994).

[2] Habeeb AAM, Marai IFM and Kamal TH. (1992). Heat stress, Chapter 2 In Farm Animals and Environment, edited by Philips and D. Piggins, Commonwealth Agriculture Bureau International, United Kingdom, 27 - 47.

[3] McMichael AJ, Ando M, Carcavallo R, Epstein P, Haines A, Jendritsky G, Kalkstein L, Kovats S, Odongo R and Patz J. (1996). Climate change and human health: an assessment by a task group on behalf of the WHO, the World Meteorological Organization, and the United Nations Environment Program.

[4] Armstrong DV. (1994). Heat stress interactions with shade and cooling. J. Dairy Sci., 77, 2044-2050.

[5] Praks J. (2010). The effect of temperature stress on dairy cows. Veterinary ruminants.

[6] Marai IFM and Habeeb AAM. (2010a). Buffalo's biological functions as affected by heat stress. A review. Livestock Science, 127, 89-109.

[7] Marai IFM and Habeeb AAM. (2010b). Review: Buffalo's reproductive and productive traits as affected by heat stress. Tropical and Subtropical Agroecosystems, 12, 193 - 217.

[8] Habeeb AAM, El-Tarabany AA, Gad AE and Atta MA. (2018a). Negative Effects of Heat Stress on Physiological and Immunity Responses of Farm Animals. International Technology and Science Publications (ITS), Agricultural Studies, 2(1), 1-18.

[9] Habeeb AAM, Gad AE, EL-Tarabany AA and Atta MAA. (2018b). Negative Effects of Heat Stress on Growth and Milk Production of Farm Animals. Journal of Animal Husbandry and Dairy Science, 2 (1),1-12.

[10] Habeeb AAM, EL-Gohary ES, Saleh HM and El-Deeb MM. (2008a). Effect of Summer Heat Stress Conditions and Feeding Protein Level on Milk Yield and Composition in Ossimi Ewes and Their Lambs Performance. Egyptian Journal of Applied Sciences, 23(6B), 409-429.

[11] Habeeb AAM, EL-Gohary ES, Saleh HM and Aboelnaga AI. (2008b). Effect of Summer Heat Stress Conditions and Feeding Protein Level on Blood Components in Ossimi Ewes and Their Suckling Lambs. Egyptian Journal of Applied Sciences, 23(6B), 388-408.

[12] Berman AJ. (2005). Estimates of heat stress relief needs for Holstein dairy cows. Journal of Animal Science, 83, 1377-1384.

[13] Berman A, Folman YM, Kaim M, Mamen Z, Herz D, Wolfenson A and Grabber Y. (1985). Upper critical temperatures and forced ventilation effects for high-yielding dairy cows in a tropical climate. Journal of Dairy Science, 68, 488-495. 
[14] Hamada T. (1971). Estimation of lower critical temperatures for dry and lactating dairy cows. Journal of Dairy Science, 54, 1704-1705.

[15] Habeeb AAM, Gad AE and Atta MAA. (2018c). Temperature-Humidity Indices as indicators to heat stress of climatic conditions with relation to production and reproduction of farm animals. International Journal of Biotechnology and Recent Advances, 1(2), 35-50.

[16] International Commission for Thermal Physiology (ICTP) (2001). Glossary of terms for thermal physiology, 3rd eds. Jpn J Physio, 51, 245-280.

[17] Kadzere CT, Murphy MR, Silanikove N and Maltz E. (2002). Heat stress in lactating dairy cows: a review. Livestock Production Science, 77, 59-91.

[18] Garner JB, Douglas MA, Williams A, Wales AWJ, Marett A, DiGiacomo B, Leury B and Hayes CD. (2017). Responses of dairy cows to short-term heat stress in controlled-climate chambers. Animal Production Science 57(7), 1233-1241.

[19] Wolff LK and Monty DEJr. (1974). The physiologic response to intense summer heat and its effect on the estrous cycle of nonlactating and lactating Holstein-Friesian cows in Arizona. American Journal of Vetreniry Research, 35, 187-192.

[20] Hales JRS, Hubbard RW and Gaffin SL. (1996). Limitation of heat tolerance. In: Handbook of Physiology (Fregly MJ, Blatteis CM, eds). New York, Oxford University Press, 279-355.

[21] Igono MO, Bjotvedt G, Sanford and Crane HT. (1992). Environmental profile and critical temperature effects on milk production of Holstein cows in the desert climate. International Journal of Biometeorology, 36, 77-87.

[22] Guyton AC. (1969). Textbook of medical physiology. 3rd (Saunders, W. B., ed.), Co. Philadelphia, 985 - 992.

[23] Agarwal A and Singh M. (2006). Impact of microclimatic modification on the production of dairy animals during summer. Indian Dairyman, 58, 49-59.

[24] Habeeb AAM. (2019). Negative effects of heat stress conditions during the hot summer season in Egypt on rabbits productivity and alleviation of these effects using some supplementary nutrients. International Journal of Agriculture and Biological Sciences, 3(6), 1-15.

[25] Habeeb AAM, Ibrahim MKh and Yousef HM. (2000). Blood and milk contents of triiodothyronine (T3) and cortisol in lactating buffaloes and changes in milk yield and composition as a function of lactation number and ambient temperature. Arab Jornal of Nuclear Sciences and Applications, 33(2), 313-322.

[26] Bray DR and Bucklin R. (1996). Recommendations for Cooling Systems for Dairy Cattle. Fact Sheet DS-29. University of Florida Cooperative Extension Service, Gainesville, Florida, 32611.

[27] Rhoads RP, Baumgard LH, Suagee JK and Sanders SR. (2013). Nutritional interventions to alleviate the negative consequences of heat stress. Advanced Nutrition, 4(3), 267-276.

[28] Hamzaoui S, Salama AAK, Caja G, Albanell E, Flores C and Such X. (2012). Milk production losses in early lactating dairy goats under heat stress. J. Dairy Sci, 95(2), 672-673.

[29] Hooda OK and Singh S. (2010). Effect of thermal stress on feed intake, plasma enzymes and blood biochemicals in buffalo heifers. Indian Journal of Animal Nutrition, 27(2), 122-127.

[30] Lacetera N, Bernabucci U, Ronchi B and Nardone A. (1996). Body condition score, metabolic status and milk production of early lactating dairy cows exposed to a warm environment. Riv. Agric. Subtrop. Trop. 90(1), 4355.

[31] Yasothai R. (2014). Effect of climate on nutrient intake and metabolism and countered heat stress by nutritional manipulation. International Journal of Science, Environment and Technology, 3(5), 1685-1690.

[32] Chandrahas SH and Das KS. (2005). Heat stress and ameliorative measures in buffaloes. Livestock International, 2, 5-8.

[33] McDowell RE, Hooven NW and Camoens JK. (1976). Effects of climate on performance of Holsteins in the first lactation. Journal of Dairy Science, 59, 965-973.

[34] Shalit O, Maltz E, Silanikove N and Berman A. (1991). Water, Na, K, and Cl metabolism of dairy cows at the onset of lactation in hot weather. Journal of Dairy Science, 74, 1874-1883.

[35] Silanikove N. (1992). Effects of water scarcity and hot environment on appetite and digestion in ruminants: a review. Livestock Production Science, 30, 175-194.

[36] Silanikove N. (2000). Effects of heat stress on the welfare of extensively managed domestic ruminants. Livestock Production Science, 67, 1-18. 
[37] Farooq U, Samad HA, Shehzad F and Qayyum A. (2010). Physiological responses of cattle to heat stress. World Applied Sciences Journal, 8, 38-43.

[38] Abdel-Samee AM, Habeeb AAM, Kamal TH and Abdel-Razik MA. (1989). The role of urea and mineral mixture supplementation in improving the productivity of heat-stressed Friesian calves in the subtropics. Proceedings of the 3rd Egyptian-British Conference on Animal Fish and Poultry Production, Alexandria University, Alexandria, Egypt, 2, 637- 641.

[39] Habeeb AAM. (2018a). Biosynthesis and Roles of Glutathione in heat Stressed Animals. International Journal of Scientific Research in Chemistry, 3 (5), 91-98.

[40] Habeeb AAM. (2018b). Oxidative Stress in Animals Exposed to Different Stressful Conditions. International Journal of Nutritional Sciences, 3(2), 1027-1029.

[41] Bernabucci U, Ronchi B, Lacetera N and Nardone A. (2002). Markers of oxidative status in plasma and erythrocytes of transition dairy cows during the hot season. Journal of Dairy Science, 85, 2173-2179.

[42] Miller JK, Brzezinska-Slebodzinska E and Madsen FC. (1993). Oxidative stress, antioxidants, and animal function. Journal of Dairy Science, 76, 2812-2823.

[43] Jones DP. (2002). The redox potential of GSH/GSSG couple: assay and biological significance. Methods Enzymol., $348,93-112$.

[44] Townsend DM, Tew KD and Tapiero H. (2003). The importance of glutathione in human disease. Biomed. Pharmacother, 57, 145-155.

[45] Guoyao Wu, Fang Yu Zhong, Sheng Yang, Lupton Joanne R and Turner Nancy D. (2004). Glutathione Metabolism and Its Implications for Health. Journal of Nutrition, 134(3), 489-492

[46] McDowell LR. (2002). Recent advances in minerals and vitamins on the nutrition of lactating cows. Pakistan Journal of Nutrition, 1, 8-19.

[47] Castillo C, Hernández J, López-Alonso M, Miranda M and Benedito JL. (2003). Values of plasma lipid hydroperoxides and total antioxidant status in healthy dairy cows: preliminary observations. Arch. Tierz., 46, 227-233.

[48] Zalba G, San Jose G, Moreno MU, Fortuno MA, Fortuno A, Beaumont FJ, San José GMA, Etayo JC and Díez J. (2001). Oxidative stress in arterial hypertension: role of NAD (P) H oxidase. Hypertension, 38, 1395-1399.

[49] Habeeb AAM, Gad AE, Teama Fatma EI and EL-Tarabany AA. (2018d). Means of Alleviation the Negative Effects of Summer Heat Stress on Animals. Journal of Animal Husbandry and Dairy Science, 2(1), 37-61.

[50] Sharaf AK, El-Darawany AA, Nasr AS and Habeeb AAM. (2019). Alleviation of the negative effects of summer heat stress by adding selenium with vitamin $\mathrm{E}$ or AD3E vitamin mixture in drinking water of female rabbits. Biological Rhythm Research. https://doi.org/DOI:10.1080/09291016.2019.1613796.

[51] Shearer JK, Bray DR and Bucklin RA. (2005).The management of heat stress in dairy cattle: What we have learned in Florida. Proc. Feed and Nutritional Management Cow College, Virginia Tech, $60-71$.

[52] El-Sobhy HE. (2005). Heat stress in female farm animals: A Review JKAU: Met., Environmental and Arid Land Agriculture Science, 165, 3 - 24.

[53] Habeeb AAM, Aboulnaga AI and Kamal TH. (2001). Heat-induced changes in body water concentration, T3, cortisol, glucose and cholesterol levels and their relationships with thermoneutral body weight gain in Friesian calves. Proceeding of the 2nd International Conference on Animal Production \& Health in Semi-Arid Areas, Suez Canal University, Faculty of Environmental Agricultural Sciences, El Arish, North Sinai, Egypt, 97- 108.

[54] Marai IFM, Habeeb AAM, Daader AH and Yousef HM. (1997). Effects of diet supplementation and body cooling on heat-stressed Friesian calves reared in high ambient temperatures in the eastern desert of Egypt. Tropical Animal \& Health Production, 4, 201-208.

[55] Habeeb AAM, Fatma Teama EI and EL-Tarabany AA. (2012a). Effect of adding selenium and vitamin E to the diet on reproductive traits of female zaraibi goats and growth of their kids. Isotope and Radiation Research, 44(3), 693-709.

[56] HabeebAAM, EL-Tarabany AA and Gad AE. (2012b). Importance of drinking water temperature for heat-stressed pregnant Ossimi ewes during the summer of Egypt. Arab Journal of Nuclear Sciences and Applications, 45(1), 223-232. 
[57] Habeeb AAM, Gad AE and El-Tarabany AA. (2012c). Effect of hot climatic conditions with different types of housing on productive efficiency and physiological changes in buffalo calves. Isotope and Radiation Research, 44(1), 109-126.

[58] Habeeb AAM, Saleh HM, Mustafa MM and Nessim MZ. (2009). Effect of a wool shearing process during the hot summer season on the physiological and nutritional performance of Ossimi lambs. Egyptian Journal of Nutrition and Feeds, 12 (3) (Special Issue), 391-405.

[59] Bewley JM, Grott MW, Einstein ME and Schutz MM. (2008). Impact of intake water temperatures on reticular temperatures of lactating dairy cows. Journal of. Dairy Science, 91(10), 3880-3887

[60] Habeeb AAM, Saleh HM, EL-Tarabany AA, Gad AE and Mostafa MM. (2010a). Impact of altered feeding time regimen under summertime environmental conditions on the physiological and nutritional performance of pregnant ewes. Isotope and Radiation Research, 42(4) (Suppl. 2), 1493-1512.

[61] Habeeb AAM, Elwan KM, Marai IFM, EL-Drawany AA and A.A.EL-Tarabany. (2010b). Effect of amelioration summer heat stress condition techniques on some blood hormones, vitamins and trace elements in rabbit bucks. Isotope and Radiation Research, 42, 4 (Suppl. 1), 1353-1373.

[62] Omnisky K, Kennedy A, Wittenberg K and Mostaghi S. (2002). Physiological and production responses to feeding schedule in lactating dairy cows exposed to short-term, moderate heat stress. Journal of Dairy Science, 85, 730 737.

[63] Habeeb AAM, Gad AE and Mustafa MM. (2018e). Improvement of Gain, Feed Efficiency and Physiological Body Functions in Native Bovine Calves during Hot Summer Season using Different Nutritional Supplements. International Journal of Nutritional Sciences, 3(1), 1021-1028.

[64] Habeeb AAM, El-Darawany AA, Nasr AS and Sharaf AK. (2019). Impact of some medicinal plant supplementation on pregnant rabbits diet during the hot summer season. Research Journal of Medicinal Plants, 13(4), 145-154.

[65] West JW, Mullinix BG and Sandifer TG. (1991). Effects of bovine somatotropin on physiologic responses of lactating Holstein and Jersey cows during hot, humid weather. Journal of Dairy Science, 74, 840 - 851.

[66] Anwar UL, Gilani H, Jabeen Q and Khan MAU. (2004). A review of medicinal uses and pharmacological activities of Nigella sativa. Pakistan Journal of Biological Science, 7, 441-451.

[67] Busquet M, Calsamiglia S, Ferret A and Kamel C. (2005). Screening for effects of plant extracts and active compounds of plants on dairy cattle rumen microbial fermentation in a continuous culture system. Animal Feed Science and Technology, 123-124, 597-613.

[68] Awadallah IM. (2002). Effect of supplementation with niacin and Nigella Sativa seeds on Friesian calves under heat stress conditions. Journal of Agriculture Sciences., Mansoura University, 27(2), 791-801.

[69] Masuda TT, Maekawa T, Hidaka K, Bando H, Takeda Y and Yamaguchi H. (2001). Chemical studies on antioxidant mechanisms of curcumin: analysis of oxidative coupling products from curcumin and linoleate. Journal of Agriculture and Food Chemistry, 49, 2539-2547.

[70] Schwartzkopf-Genswein KS, Beauchemin KA, McAllister TA, Gibb DJ, Streeter M and Kennedy AD. (2004). Effect of feed delivery fluctuations and feeding time on ruminal acidosis, growth performance and feeding behavior of feedlot cattle. Journal of Anim. Science, 82, 3357-3365.

[71] Simone H. (2010). Heat stress in beef cattle, Tech Line, Products and answers that Work, Hubbard Beef Solutions.

\section{How to cite this article}

Habeeb AAM, Osman SF and Gad AE. (2020). Signs of heat stress and some steps to reduce the negative effects on animals. GSC Advanced Research and Reviews, 4(1), 46-58. 